\title{
1 The background
}

\author{
CHARLES D SHAW
}

\section{Summary and conclusions}

Methods of reviewing health care already exist in Britain, but the debate continues about how practical and acceptable such a review is. The many different terms used to describe review only confuse the issue. "Audit" is a useful term for describing the review of medical work by medical people. This can be divided into "internal audit," or peer review, and "external audit"that is, review by organisations outside hospital and general practice. The concepts of internal and external audit have a great impact upon the attitudes held by the medical profession about audit. The shortcomings of audit by the professional standards review organisations in the United States are not inevitable in Britain.

\section{Introduction}

Vexation is part of the natural history of medical audit. The question of who should scrutinise clinical work and how has generated a lengthy debate in the United States, Canada, and Australia-and now Britain. The medical profession in these countries has rightly argued that it is inappropriate for the methods evolved in one country for medical audit to be applied unmodified in another. Although there is disagreement and conflicting evidence about audit, certain conclusions have emerged that are common to all these countries and that are now evident in Britain. If the medical profession in Britain fails

\footnotetext{
Gloucestershire Area Health Authority, Cheltenham GL50 2QN, Gloucestershire

CHARLES D SHAW, MB, BS, senior registrar in community medicine (previous appointments: representative for the Canadian Council on Hospital Accreditation, Ottawa, Canada, and medical director, King Edward VII Memorial Hospital, Bermuda)
}

to take stock of what has been learned about medical audit abroad, the same mistakes will no doubt be made again.

Few subjects evoke as much controversy in the medical profession as medical audit. To some it means assuring clinical standards; to others it is the opposite. Even so, many doctors are coming round to the conclusion that "someone ought to do something about it." What should be done and who should do it would be clearer if there was agreement on what audit is intended to achieve. The widely divergent views on this foster suspicion and distrust of the whole subject by the medical profession, undoubtedly discrediting audit more than it deserves. Even the terminology is forbidding.

\section{Audit by any other name}

It is unfortunate that the term "audit"-more usually associated with accountancy-implies numerical review by an outside investigator directed at, among other things, the prevention of fraud. However inappropriately, this connotation has been carried over to what has otherwise been called "medical care evaluation," "clinical and administrative review," "self scrutiny," and a confusing selection of synonyms designed to avoid the misnomer of "medical audit" (table I). Duncan has suggested that "quality assurance" should be applied to the subject in general and "medical audit" to the specific process. By combining any one word from each column in table $I$ in order it is possible to produce 96 phrases that either have been or can be used to mean review of health care.

\section{Various methods of review}

Such a cynical simplification conceals important differences between the aims and methods implied in column three of table I, however. Indeed, failure to distinguish between medical audit and monitoring, for example, may account for some of 
TABLE I-Audit by any other name?

\begin{tabular}{lll}
\hline Medical & Care & Evaluation \\
Health & Standards & Assessment \\
Clinical & Activity & Assurance \\
Professional & Quality & Audit \\
& & Review \\
& & Monitoring \\
\hline
\end{tabular}

the undeserved disrepute of audit. Doll says that monitoring in the National Health Service implies not only the collection of intelligence to measure progress but also an element of control by health authorities and the Department of Health and Social Security. While such a method may be appropriate for administration, it is the least acceptable and probably least effective form of audit when applied to the care of individual patients.

Evaluation is defined by the World Health Organisation as "the systematic and scientific process of determining the extent to which an action or set of actions was successful in the achievement of predetermined objectives." Only by using objective research methods can specified patterns of clinical management be related accurately to their effect on clinical outcome. Since most methods of clinical audit rely heavily on the assumption that good care produces good outcomes, audit and evaluation are thus complementary. Although some maintain that these are discrete entities, in practice many audit studies include an element of research.

The Alment Committee report on competence to practise interpreted medical audit as "the sharing by a group of peers of information gained from personal experience and/or medical records in order to assess the care provided to their patients, to improve their own learning, and to contribute to medical knowledge." This is less restrictive in terms of both method and objectives than the American view of Slee (quoted by McWhinney) that medical audit is "the evaluation of the quality of medical care as reflected in medical records."

Sanazaro states the American Medical Association's definition of peer review as the "evaluation by practising physicians of the quality and efficiency of services ordered by other practising physicians." The Welsh working party on medical audit by peer review defined "peers" as "clinicians, all practising in a comparable situation," reflecting the view of the Alment Committee as "doctors who practise in the same specialty and in broadly similar conditions of practice."

These differences are far from academic, and failure to recognise them has caused people in Britain to assume that all the misgivings about audit in North America also apply here. Moreover, a more liberal interpretation will show that to some extent both medical audit and peer review have long been a part of British medical practice.

\section{Internal versus external audit}

Internal, clinical medical audit is quite separate from external, non-clinical inspection. The difference between the two concepts may be considered in two dimensions-the extent to which they are external and the extent to which they are non-clinical. At the one extreme of the internal/external dimension is the practitioner reviewing his own work and at the other extreme the review of that work by an outside body separated by distance, experience, and values. The clinical/ non-clinical spectrum ranges from review by practising clinicians to review by non-medical administrators, community health councils, and lay bodies.

Using this framework, the relations between existing methods for review of health services can be illustrated as in table II.
The exact positions of the designations are arguable, but the idea of a continuum is evident. Although not directly relevant to Britain, professional standards review organisation (PSRO) has been included since many of its characteristic shortcomings have been attributed to medical audit in general. The PSRO structure was devised by the United States government primarily to control the spiralling cost of government-funded health schemes. It was imposed upon the medical profession by federal statute, it is not linked to continuing education, and it has the sanction of withholding payment.

Using table II generalisations can be made about what is implied in the review of medical care at either end of the spectrum, internal versus external and clinical versus nonclinical (table III). The external, non-clinical audit may be summarised as statutory and regulatory with implied sanctions. The internal, clinical audit may be summarised as voluntary, educational, and without sanctions.

If "medical audit" was understood in Britain to refer only to self-audit and peer review, much confusion and antipathy would be avoided.

TABLE II-Audit of health care

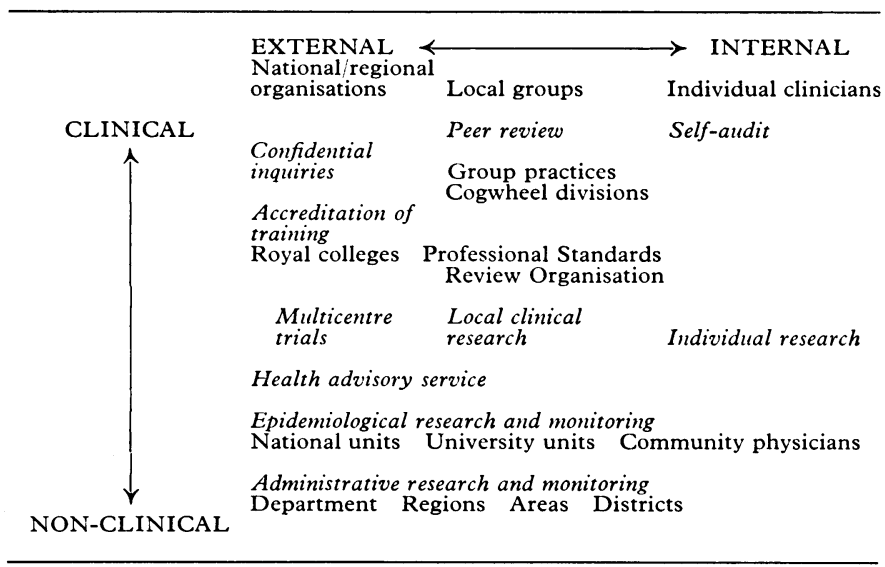

TABLE III-General characteristics of review mechanisms

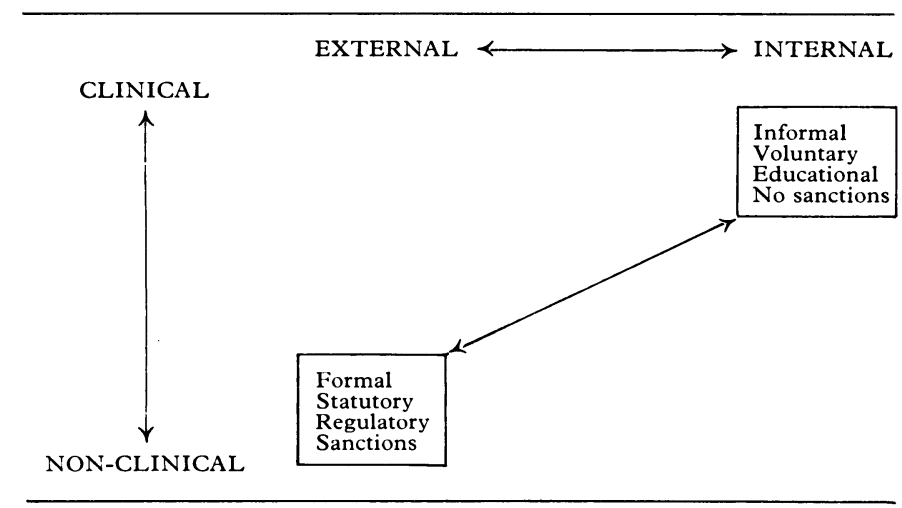

\section{Input, process, and outcome}

When the decision has been made to review health care, the subject may be approached from many different directions and, in theory, the same conclusions arrived at. But in practice different approaches yield different conclusions, there is no universal means of validating health measures, and even the audit enthusiasts acknowledge that each approach has its weaknesses.

The most quoted model of patient care audit is input, process, and outcome. An example from the manufacturing industry 
from which the model was borrowed may be helpful: raw materials (inputs) are handled in a certain manner (process) to produce a finished article (output). Each of these elements can be defined in the objective terms of dimensions, numbers, or money as measures for audit. In medicine these elements are often referred to as structure (representing resources), process (the way in which the resources are applied), and outcome (the result of the intervention).

In transferring the industrial model to health care, however, several problems arise. Even if structure and outcome can be measured, the relation between them is variable and badly defined, the quality of care is hard to quantify, and in many conditions the ideal outcome is controversial. It has been suggested, therefore, that patient risk factors and social acceptability should be regarded as separate elements of the model since they appreciably modify the relation between structure and outcome.

\section{OUTCOME}

Ideally an audit of the quality of medical care would focus on the difference between the outcome that is desired and that which actually occurs. In most practice both are hard to define and may occur so long after treatment that many other factors will have intervened to confuse the issue. The concept of "intermediate outcome," such as immunisation take-up rates, is a more practical and more sensitive indicator for outcome than the crude but basic measure of mortality, to which studies often resort.

\section{PROCESS}

Alternatively, audit may focus on the process, such as operation, regimen, or medication, on the assumption that good treatment (as confirmed, for example, by clinical trials) will lead to a good outcome. Some argue that this assumption is invalid since many treatments have never been studied in a controlled. setting. And even if they have, are the in vitro results of research applicable to the in vivo reality of everyday practice?

\section{STRUCTURE}

Audit of structure is even further removed from the outcome of treatment and is, at best, a very indirect measure. Its merit is that resources can be readily measured and the information is accessible. Unfortunately, it is this very convenience (and the absence of better measures) that tempts health administrators to regard norms of input as a substitute for standards of outcome.

\section{Measure of quality of care}

Standards, not numerical norms, are the measure of the quality of care, but the medical profession has been reluctant to define standards explicitly. So long as good medicine remains implicit, its evaluation by audit or any other method will remain haphazard.

\section{Bibliography}

Calne RY. Surgical self-scrutiny. Lancet 1974 ;ii:1308-9.

Cochrane AL. Effectiveness and efficiency. London: Nuffield Provincial Hospitals Trust, 1972.

Committee of enquiry into competence to practise. Report. Alment EAJ, chairman. London, 1976.

Doll R. Monitoring the National Health Service. Proc R Soc Med 1973;66: 729-40.

Donabedian A. Evaluating the quality of medical care. Milbank Mem Fund $Q$ $1966 ; 44$,suppl:166-206.

Duncan A. Quality assurance: what now and where next ? $\mathrm{Br}$ Med $\mathcal{F} 1980$; $280: 300-2$

Editorial. Medical audit in general practice. 7 R Coll Gen Pract 1979;29:699.

General Medical Services Committee (Wales). Report of a working party on medical audit by peer review. Williams DL, chairman. 1975.

Hogarth J. Glossary of health care terminology. Copenhagen: World Health Organisation, 1975.

McColl I. Medical audit in British hospital practice. Br $\mathcal{F}$ Hosp Med 1979; $22: 485-9$.

McLachlan G. Introduction and perspective. In: McLachlan G, ed. $A$ question of quality? Oxford: Oxford University Press, 1976:3-20.

McWhinney IR. Medical audit in North America. Br Med 7 1972;ii :277-9.

Matthews MB. Self-assessment programmes and aspects of audit. $\mathcal{F} R$ Coll Physicians Lond 1979;3:139-42.

Mourin K. Audit in general practice. $\mathcal{f} R$ Coll Gen Pract 1975;25:682-3.

Rose JC. Recertification and peer review in the United States. $\mathcal{F} R$ Coll Gen Pract $1974 ; 24: 595-7$.

Sanazaro PJ. Experience in the U.S.A. Br Med 7 1974; i :271-4

Stott NCH, Davis RH. Clinical and administrative review in general practice. $\mathcal{F} R$ Coll Gen Pract $1975 ; 25: 888-96$.

Wilson LL, Larkins N. Peer review. Med f Aust 1977;i,suppl 2:7-24.

This is the first of five articles on theoretical and practical audit in hospitals and general practice in Britain.

Readers may obtain specific references from the author.

No reprints will be available.
"Convenience" milk substitutes are being marketed on an increasing scale. What is the calorie value of these substances and what type of fat do they contain?

In most cases the calorific value of the convenience milk substitutes is virtually the same as the equivalent amount of whole milk. The fat content may be slightly lower but not significantly in view of the small amounts that are, for example, added to coffee. The fats used in these preparations are mixtures of vegetable fat, which may be slightly less saturated than milk fat. Highly polyunsaturated fat mixtures are not used in the preparations because of problems with stability.

Two years ago a woman of 77 did not need glasses for distance but since taking disopyramide (Rythmodan) $100 \mathrm{mg}$ thrice daily (she has been treated with sotalol hydrochloride for moderate hypotension) her usual acuity has diminished and she now needs glasses for distance and a stronger lens for reading. Could there be any association?

Blurred vision is a common side effect of disopyramide owing to its anticholinergic properties like those of atropine. Anticholinergic drugs produce dilatation of the pupil and reduce accommodation.
Visual disturbance with beta-adrenergic blocking agents, such as sotalol hydrochloride, may occasionally occur but is usually transitory and unimportant. Disopyramide interacts with beta-adrenergic blocking drugs, and therefore in sensitive individuals the side effects of both the drugs could be augmented when used together. Anticholinergic drugs should not be used in patients with potential angleclosure glaucoma.

\section{Do fluoride salts cross the placental barrier?}

Fluoride salts do cross the placenta to a limited degree. Animal studies have shown that radioactive fluoride accumulates in the placenta in the same site as calcium phosphates, and the small amount that enters the fetus is rapidly concentrated in the mineralised part of the fetal skeleton. ${ }^{1}$ Human neonatal bones and teeth contain fluoride, and the placenta seems to have a regulatory function for fluoride which is not operative when maternal intake of fluoride is low but will prevent excess fluoride entering the fetus when the mother ingests highly fluoridated water or fluoride tablets.

\footnotetext{
${ }^{1}$ Ericsson Y, Ullberg S. Autoradiographic investigations of the distribution of F18 in mice and rats. Acta Odontol Scand 1958;13:363-74

edalic in the human fetus at low and high F-intake. $₹$ Dent Res $1964 ; 43: 669-71$.
} 